\title{
Valor nutritivo de rações contendo casca do grão de soja em substituição ao milho moído para cabritos Saanen ${ }^{1}$
}

\author{
Claudete Regina Alcalde ${ }^{2}$, Maximiliane Alavarse Zambom ${ }^{3}$, Gabriella de Oliveira \\ Passianoto $^{4}$, Luciano Soares de Lima ${ }^{5}$, Lucia Maria Zeoula ${ }^{2}$, Juliano Hideo Hashimoto ${ }^{3}$
}

\author{
1 Projeto financiado pela Fundação Araucária. \\ 2 Departamento de Zootecnia da Universidade Estadual de Maringá-UEM. \\ ${ }^{3}$ Pós-graduação em Zootecnia, UEM. \\ ${ }^{4}$ Curso de Graduação em Zootecnia. Bolsista IC/CNPq. \\ ${ }^{5}$ Curso de Graduação em Zootecnia. Bolsista PIBIC/CNPq.
}

RESUMO - Este trabalho foi conduzido com os objetivos de avaliar a ingestão e a digestibilidade da matéria seca e dos nutrientes e estimar o valor energético de rações com 0; 25; 50; 75 ou 100\% de casca do grão de soja em substituição ao milho moído na dieta de cabritos. As rações foram compostas de feno de aveia, milho moído e/ou casca do grão de soja, farelo de soja e suplemento mineral. Foram utilizados cinco cabritos da raça Saanen $(32,44 \pm 4,00 \mathrm{~kg})$ alojados em gaiolas de digestibilidade em delineamento quadrado latino $5 \times 5$. Foram realizadas coletas totais de fezes utilizando-se sacolas de lona. Cada período foi composto de 12 dias (sete dias para adaptação à ração e cinco dias para coletas). As ingestões de matéria seca (MS), matéria orgânica (MO), proteína bruta (PB), carboidratos totais (CT) e nutrientes digestíveis totais (NDT) não foram alteradas pela inclusão de casca do grão de soja nas rações. No entanto, para a ingestão de extrato etéreo, FDN e amido, houve efeito linear dos níveis de casca do grão de soja. Para as digestibilidades da MS, MO, PB, CT, FDN, amido e para os NDT, foram observados efeitos quadráticos e a digestibilidade do extrato etéreo não foi alterada. A inclusão de casca do grão de soja em níveis de até $75 \%$ nas rações de cabritos melhora a digestibilidade e o valor energético das dietas, mantendo-se a viabilidade econômica.

Palavras-chave: caprinos, coleta total, digestibilidade, energia, subproduto da soja

\section{Nutritive value of rations containing soybean hulls in replacement of ground corn, in Saanen kids}

\begin{abstract}
The objective of this study was to evaluate the dry matter and nutrient intake and digestibility and to estimate the energy value of diets with the inclusion of soybean hulls (0, 25, 50, 75 and 100\%) replacement of ground corn in the diet of kids goats. The rations consisted of oat hay, ground corn and/or soybean hulls, soybean meal and mineral supplement. Five Saanen kid goats $(32.44 \pm 4.00 \mathrm{~kg})$, housed in digestibility cages, in a $5 \times 5$ Latin square design were used. Total feces were collected with canvas bags. Each period consisted of 12 days, seven days to adapt to the rations and five days for collections. The intake of dry matter (DM), organic matter (OM), crude protein (CP), total carbohydrates (TC) and total digestible nutrients (TDN) were altered by the inclusion of soybean hulls in the rations. However, for the intakes of ether extract, NDF and starch there was a linear effect. Quadratic effects were observed for the digestibility of DM, OM, CP, TC, NDF, starch and the TDN but the ether extract digestibility was not altered. The inclusion of the soybean hulls up to $75 \%$ in the rations of kid goats improved digestibility, resulting in higher energy value with economic viability.
\end{abstract}

Key Words: digestibility, energy, goats, soybean byproduct, total feces

\section{Introdução}

O estudo do valor nutritivo dos subprodutos originados da produção agrícola e da agroindústria na alimentação dos ruminantes é realizado há anos, em razão da necessidade de fornecimento de alimentos alternativos e viáveis economicamente, sem concorrência direta com a alimentação humana.

Em animais ruminantes, quando o milho é utilizado em grandes proporções, ocorre mudança no ecossistema ruminal, devido ao seu alto teor de amido (68\% a $72 \%$ ), que promove o aumento na produção de ácidos no rúmen, 
principalmente o ácido lático (Nocek, 1997) que pode causar redução do pH ruminal e prejudicar a degradabilidade da fibra.

A casca do grão de soja (CGS) é um subproduto da agroindústria classificado pelo NRC (2001) como um alimento volumoso seco e uma de suas características é a presença de pectina na parede celular. Este carboidrato é altamente degradável e seu processo de fermentação ruminal tende a produzir alta razão acetato:propionato e quantidade relativamente baixa de lactato (Hatfield \& Weimer, 1995).

Zambom et al. (2001) realizaram ensaios de digestibilidade in vitro da casca do grão de soja pelo método de rúmen artificial utilizando sacos 557 ANKOM $^{\circledR}$ e observaram valores de 94,96\% e 95,69\% para matéria seca e parede celular, respectivamente.

Assim, fontes de fibra com boa degradação, como a casca do grão de soja, possuem potencial para substituição a grãos de cereais como o milho para melhorar o padrão de fermentação ruminal e evitar distúrbios metabólicos (Ipharraguerre \& Clark, 2003). A inclusão da casca do grão de soja no concentrado de bovinos na fase de engorda corresponde a $74 \%$ a $80 \%$ do valor nutricional do grão de milho (Ludden et al., 1995). A substituição parcial ou total do milho pela casca do grão de soja na dieta de novilhos (Galloway et al., 1993) e de cabritos (Hashimoto et al., 2007) melhora a digestibilidade da fibra.

Para se obter o máximo potencial produtivo e reprodutivo dos animais, é fundamental o conhecimento do valor nutritivo dos alimentos, para a adequada ingestão de energia, proteínas, minerais e vitaminas. Zambom et al. (2007), trabalhando com cabras em lactação observaram efeito positivo da substituição do milho pela casca do grão de soja nas rações na digestibilidade da matéria seca e dos nutrientes, sem alteração na produção e qualidade do leite.

Neste contexto, este trabalho foi realizado com os objetivos de avaliar a ingestão e digestibilidade da matéria seca e dos nutrientes e estimar o valor energético de rações contendo casca do grão de soja em substituição ao milho moído em cabritos Saanen.

\section{Material e Métodos}

O experimento foi conduzido no setor de metabolismo da Fazenda Experimental de Iguatemi, pertencente à Universidade Estadual de Maringá (UEM).

Foram utilizados cinco cabritos da raça Saanen, nãocastrados $(32,44 \pm 4,00 \mathrm{~kg})$, alojados em gaiolas de digestibilidade, equipadas com comedouro e bebedouro. Os animais foram distribuídos em quadrado latino $5 \times 5$, composto de cinco cabritos e cinco períodos. O período experimental foi de 60 dias, constituídos de cinco períodos de 12 dias, com sete dias para adaptação à ração e cinco dias para coleta.

Os animais foram pesados ao início e final de cada período para ajuste da quantidade de ração fornecida, em 3,5\% de ingestão de matéria seca em relação ao peso corporal. A ração foi pesada diariamente e fornecida uma vez ao dia (às 8 h) e a água, fornecida à vontade.

Os tratamentos consistiram da substituição do milho moído pela casca do grão de soja (CGS) nas rações nos seguintes níveis: 0; 25; 50; 75 e 100\%. As rações foram compostas por feno de aveia e concentrado à base de farelo de soja, milho moído e/ou casca do grão de soja , calcário, fosfato bicálcico e suplemento mineral. A formulação das rações foi com base na matéria seca, para fornecimento médio de $69 \%$ de NDT, correspondente a 2,50 Mcal de energia metabolizável por kg de matéria seca e 16\% de proteína bruta (Tabelas 1 e 2).

A ingestão de matéria seca foi determinada pela diferença entre a quantidade fornecida e as sobras diárias. As ingestões dos nutrientes contidos na matéria seca foram estimadas a partir das análises químico-bromatológicas. No início de cada período, foram amostradas as rações e obtidas amostras compostas por tratamento para realização das análises laboratoriais.

As coletas totais de fezes foram realizadas com auxílio de sacolas de lona adaptadas aos animais. As fezes foram coletadas no período da manhã (8h30) e pesadas, homogeneizando e retirando $10 \%$ do total para obtenção de amostras compostas por animal e por período de coleta.

Tabela 1 - Composição dos alimentos

\begin{tabular}{|c|c|c|c|c|}
\hline \multirow[t]{2}{*}{ Nutriente } & \multicolumn{4}{|c|}{ Alimento } \\
\hline & Milho moído & Farelo de soja & Casca do grão de soja & Feno de aveia \\
\hline Matéria seca (\%) & 89,85 & 90,50 & 92,60 & 91,38 \\
\hline Matéria orgânica (\%MS) & 98,93 & 93,33 & 92,78 & 86,56 \\
\hline Proteína bruta (\%MS) & 8,38 & 49,56 & 15,45 & 7,23 \\
\hline Extrato etéreo (\%MS) & 3,59 & 2,10 & 2,43 & 0,94 \\
\hline Fibra em detergente neutro (\%MS) & 12,34 & 14,85 & 60,74 & 76,08 \\
\hline Fibra em detergente ácido (\%MS) & 3,81 & 10,32 & 46,81 & 36,93 \\
\hline Amido (\%MS) & 77,11 & 1,22 & 0,14 & 3,48 \\
\hline
\end{tabular}


Tabela 2 - Composição das rações experimentais

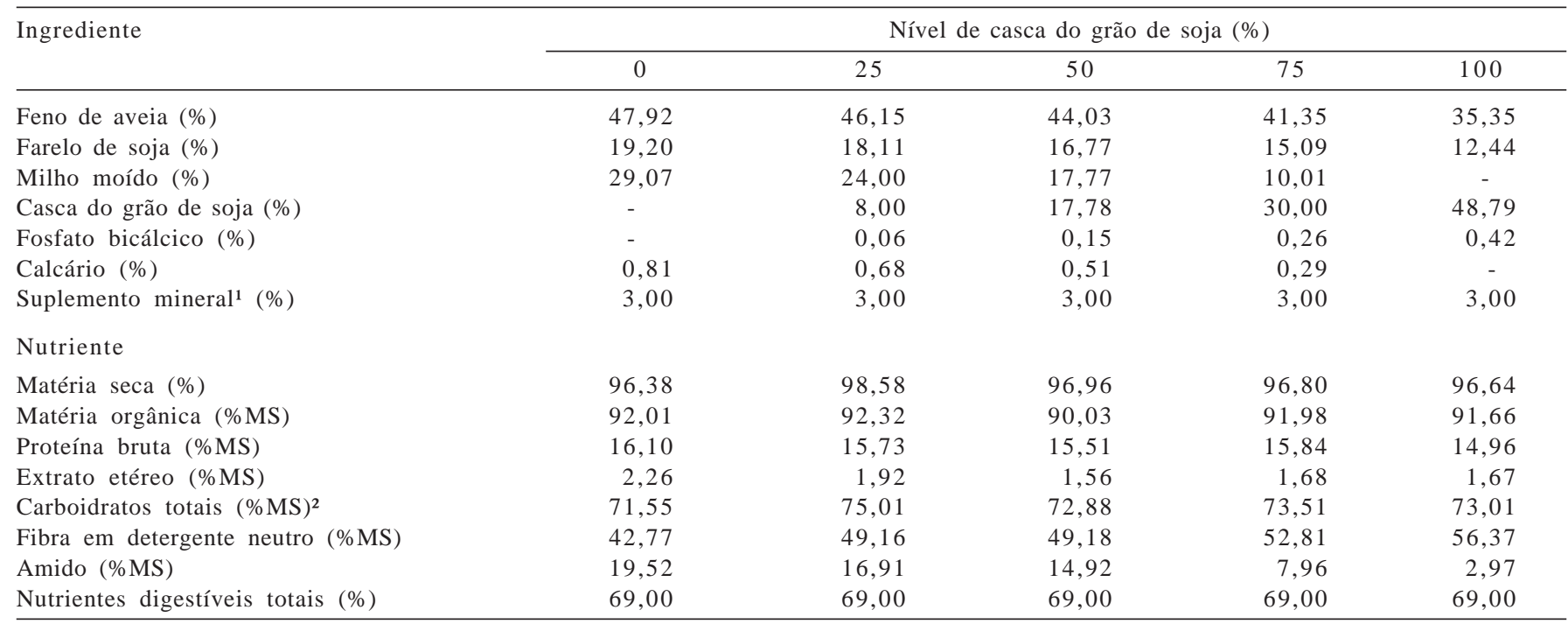

${ }^{1}$ Composição química, por kg do produto: Ca - 130 g; P - 65 g; Mg - 19 g; S - 13 g; Na - 93 g; Cl - 145 g; Se - 10 mg; Cu - 850 mg; Fe - 700 mg; Zn - 2.750 mg; Mn - 1.000 mg; I - 120 mg; Co - 70 mg; F - 650 mg.

${ }^{2}$ Estimado pela fórmula de Sniffen et al. (1992): CT $=100-(\% \mathrm{~PB}+\% \mathrm{EE}+\%$ Cinzas $)$.

As amostras das rações e fezes foram armazenadas em freezer e, posteriormente, pré-secas em estufa com ventilação forçada de ar, a $55^{\circ} \mathrm{C}$, durante 72 horas; e trituradas em moinhos com crivos de $1 \mathrm{~mm}$. Nas amostras foram determinados os teores de matéria seca (MS), proteína bruta (PB), extrato etéreo (EE) e cinzas, segundo metodologias descritas por Silva \& Queiroz (2002); com a matéria orgânica (MO) estimada a partir da determinação das cinzas. O teor de fibra em detergente neutro foi determinado segundo metodologia de Van Soest et al. (1991) e, para o teor de amido, foi utilizado o método enzimático de Poore et al. (1989), adaptado por Pereira \& Rossi (1995).

Os carboidratos totais (CT) e os nutrientes digestíveis totais (NDT) foram estimados segundo as equações descritas por Sniffen et al. (1992): CT (\%) = $100-(\% \mathrm{~PB}+$ $\% \mathrm{EE}+\%$ Cinzas) e NDT $=\mathrm{PBD}+2,25 \times \mathrm{EED}+\mathrm{CTD}$, em que $\mathrm{PBD}=$ proteína bruta digestível, $\mathrm{EED}=$ extrato etéreo digestível e CTD = carboidratos totais digestíveis.
A análise estatística das variáveis estudadas foi realizada utilizando-se o programa SAEG (Sistema para Análises Estatísticas e Genéticas), desenvolvido pela Universidade Federal de Viçosa (UFV, 1997). A análise de variância foi realizada por análise de regressão considerando os níveis de casca do grão de soja ( $0 ; 25 ; 50 ; 75$ ou 100\%).

Foi realizada pesquisa de mercado na região de Maringá, no mês de outubro de 2008, dos preços dos ingredientes, para avaliar os custos das rações.

\section{Resultados e Discussão}

As ingestões de matéria seca (MS), matéria orgânica, proteína bruta, carboidratos totais e nutrientes digestíveis totais não diferiram $(\mathrm{P}>0,05)$ entre os níveis de casca do grão de soja (Tabela 3). No entanto, para as ingestões de extrato etéreo e amido, houve efeito linear negativo e, para fibra em detergente neutro, efeito linear positivo.

Tabela 3 - Ingestões de nutrientes em cabritos Saanen alimentados com rações contendo casca do grão de soja em substituição ao milho moído

\begin{tabular}{|c|c|c|c|c|c|c|c|c|}
\hline \multirow[t]{2}{*}{ Item } & \multicolumn{5}{|c|}{ Nível de casca de grão de soja (\%) } & \multirow[t]{2}{*}{ Regressão } & \multirow[t]{2}{*}{$\mathrm{R}^{2}$} & \multirow[t]{2}{*}{ CV (\%) } \\
\hline & 0 & 25 & 50 & 75 & 100 & & & \\
\hline Matéria seca & 1,122 & 1,195 & 1,068 & 1,168 & 1,105 & $\mathrm{Y}=1,132$ & $\mathrm{NS}^{1}$ & 9,27 \\
\hline Proteína bruta & 0,181 & 0,188 & 0,165 & 0,185 & 0,165 & $Y=0,177$ & NS & 9,36 \\
\hline Extrato etéreo & 0,025 & 0,022 & 0,016 & 0,019 & 0,018 & $\mathrm{Y}=0,024-0,000069 \mathrm{X}$ & 0,60 & 9,88 \\
\hline Carboidratos totais & 0,803 & 0,896 & 0,777 & 0,857 & 0,807 & $\mathrm{Y}=0,828$ & NS & 9,21 \\
\hline Nutrientes digestíveis totais & 0,690 & 0,750 & 0,680 & 0,790 & 0,700 & $\mathrm{Y}=0,719$ & NS & 10,12 \\
\hline
\end{tabular}

${ }^{1} \mathrm{NS}=\mathrm{P}>0,05$ 
O mesmo comportamento de ingestão da matéria seca e dos nutrientes foi observado por Hashimoto et al. (2007) no desempenho de cabritos Boer $\times$ Saanen $(25,75 \pm 3,80 \mathrm{~kg})$ e por Zambom et al. (2007) em cabras Saanen $(52,35 \mathrm{~kg} \pm 7,46)$ em lactação alimentados com rações contendo 0; 50 e 100\% de casca do grão de soja em substituição ao milho.

A ingestão de matéria seca não reduziu com o aumento da ingestão da fibra da casca do grão de soja, possivelmente devido à composição química deste alimento que contém 65,6\% de FDN; 43,0\% de celulose; 17,8\% de hemicelulose (Ipharraguerre \& Clark, 2003). Além desses componentes da parede celular, a pectina da casca do grão de soja corresponde a 62,4\% dos carboidratos não-fibrosos (CNF), o que equivale a 8,8\% da MS (NRC, 2001). Embora faça parte da parede celular, a pectina é solúvel em detergente neutro e, por este motivo, é computada junto ao teor de CNF. Esses componentes da casca do grão de soja colaboram para a boa degradabilidade e não alteram a ingestão de matéria seca.

Foram observados efeitos quadráticos $(\mathrm{P}<0,05)$ para as digestibilidades de MS, MO, PB, CT, FDN, amido e os nutrientes digestíveis totais (NDT), que foram maiores no nível de até $75 \%$ de casca de grão de soja (Tabela 4). Galloway et al. (1993), Gomes (1998) e Mendes et al. (2005), estudando a substituição total e/ou parcial do milho pela casca do grão de soja em bovinos confinados, não obtiveram diferenças entre os tratamentos para as digestibilidades da MS e MO. No entanto, Hashimoto et al. (2007), trabalhando com cabritos ( $25,75 \pm 3,80 \mathrm{~kg}$ ), observaram que a inclusão de casca do grão de soja na ração reduziu as digestibilidades da MS, MO, PB e CT. Entre caprinos e bovinos, em razão da diferença nas fases fisiológicas, a inclusão total da casca do grão de soja em substituição ao milho nas rações pode ser limitada.

A FDN apresentou máxima digestibilidade em 76,51\% de casca do grão de soja nas rações. No entanto, a digestibilidade observada no nível $100 \%$ casca do grão de soja foi ainda maior que nos níveis 0; 25 e 50\% casca do grão de soja, portanto, mesmo não sendo o ponto de máximo, o milho pode ser $100 \%$ substituído pela casca do grão de soja.

A boa degradação da FDN apresentada pelas rações contendo casca do grão de soja decorre da composição química desse alimento, que contém alto teor de celulose e hemicelulose e baixo teor lignina (Ipharraguerre \& Clark, 2003). Estas características permitem maior disponibilidade do alimento à ação dos microrganismos ruminais. Além disso, a pectina está presente na parede celular da casca do grão de soja e colabora para um padrão de fermentação ruminal mais adequado para a degradação da fibra, devido à redução na produção de lactato (Hatfield \& Weimer, 1995) proveniente de fontes de amido.

A inclusão de 50 e 100\% de casca do grão de soja em substituição ao milho nas rações de cabritos mestiços Boer + Saanen melhorou a digestibilidade da FDN (Hashimoto et al., 2007). Em cabras Saanen em lactação, os coeficientes de digestibilidade da FDN de rações com 50 e $100 \%$ de casca do grão de soja em substituição ao milho também foram aumentados (Zambom et al., 2008). Estes estudos ajudam a confirmar a boa utilização da fibra da casca do grão de soja em caprinos, que resulta em efeito associativo positivo, podendo substituir o milho parcial ou totalmente.

A inclusão da casca do grão de soja não alterou $(\mathrm{P}>0,05)$ a digestibilidade do EE. Entretanto, Hashimoto et al. (2007) observaram maior digestibilidade do EE em cabritos recebendo rações sem casca do grão de soja e Gomes (1998) observou em bovinos redução na digestibilidade do EE ao substituírem o milho pela casca do grão de soja. Os resultados de digestibilidade do extrato etéreo podem muitas vezes, ser reflexos diretos do teor do nutriente nas rações, porém neste experimento a redução no teor de EE provocada pela inclusão de casca do grão de soja não foi suficiente para alterar a digestibilidade.

Tabela 4 - Digestibilidade dos nutrientes em cabritos Saanen alimentados com rações contendo casca do grão de soja (CGS) em substituição ao milho moído

\begin{tabular}{|c|c|c|c|c|c|c|c|c|c|}
\hline \multirow[t]{2}{*}{ Digestibilidade } & \multicolumn{5}{|c|}{ Nível de casca de grão de soja (\%) } & \multirow{2}{*}{\multicolumn{2}{|c|}{ Regressão }} & \multirow[t]{2}{*}{$\mathrm{R}^{2}$} & \multirow[t]{2}{*}{ CV $(\%)$} \\
\hline & 0 & 25 & 50 & 75 & 100 & & & & \\
\hline Matéria seca (\%) & 65,815 & 65,471 & 68,821 & 70,473 & 67,002 & $\mathrm{Y}=64,905$ & $5+0,120 X-0,00091 X^{2}$ & 0,56 & 4,23 \\
\hline Matéria orgânica (\%) & 65,852 & 64,56 & 67,848 & 70,246 & 66,838 & $\mathrm{Y}=64,831$ & $+0,089 X-0,00059 X^{2}$ & 0,42 & 4,35 \\
\hline Proteína bruta (\%) & 68,035 & 67,796 & 71,235 & 75,134 & 70,364 & $Y=66,885$ & $+0,146 X-0,000983 X^{2}$ & 0,56 & 4,54 \\
\hline Extrato etéreo (\%) & 68,256 & 65,833 & 60,212 & 63,403 & 61,541 & & $\mathrm{Y}=63,849$ & $\mathrm{NS}^{2}$ & 8,91 \\
\hline Carboidratos totais (\%) & 65,832 & 66,920 & 69,289 & 71,192 & 67,865 & $\mathrm{Y}=65,225$ & $+0,139 X-0,00106 X^{2}$ & 0,75 & 4,11 \\
\hline Fibra em detergente neutro (\%) & 42,469 & 53,077 & 56,527 & 60,666 & 58,642 & $\mathrm{Y}=43,344$ & $+0,430 X-0,00281 X^{2}$ & 0,98 & 5,88 \\
\hline Amido (\%) & 98,333 & 98,534 & 99,103 & 98,767 & 96,310 & $\mathrm{Y}=98,081$ & $1+0,057 X-0,00072 X^{2}$ & 0,87 & 1,07 \\
\hline Nutrientes digestíveis totais ${ }^{1}$ (\%) & 61,897 & 63,607 & 64,605 & 67,433 & 62,968 & $\mathrm{Y}=61,406$ & $6+0,144 X-0,00120 X^{2}$ & 0,65 & 3,99 \\
\hline
\end{tabular}

${ }^{1}$ Estimado pela fórmula de Sniffen et al. (1992): NDT $=$ PBD + 2,25 $\times$ EED + CTD.

${ }^{2} \mathrm{NS}=\mathrm{P}>0,05$. 
Os resultados de digestibilidade comprovaram que a casca do grão de soja é uma alternativa para substituição do grão de milho em rações de cabritos Saanen e seu preço corresponde a $81,8 \%$ do preço de mercado em relação ao milho. O estudo econômico das rações com adição de casca do grão de soja no mês de outubro de 2008 na região de Maringá mostrou valores médios de R \$0,44/kg; R \$ 0,43/kg; $\mathrm{R} \$ 0,42 / \mathrm{kg} ; \mathrm{R} \$ 0,41 / \mathrm{kg}$ e $\mathrm{R} \$ 0,39 / \mathrm{kg}$ para os respectivos níveis 0; 25; 50; 75 e 100\% casca do grão de soja (Tabela 5). Esses valores indicam que, com o aumento no nível de casca do grão de soja, o custo das rações é reduzido.
Hashimoto et al. (2007), avaliaram o desempenho de cabritos Boer $\times$ Saanen recebendo rações com casca do grão de soja em substituição ao milho em níveis de 0; 50 e $100 \%$ e obtiveram o quilo comercial da carcaça ao custo $\mathrm{R} \$ 11,40 ; \mathrm{R} \$ 5,56$ e $\mathrm{R} \$ 8,64$ para 0; 50 e 100\% de casca do grão de soja, respectivamente.

No entanto, para produção de leite de cabras, Zambom (2009) avaliou a substituição (0; 50 e 100\%) do milho pela casca do grão de soja e não observou diferença econômica, o que prioriza a avaliação do preço no mercado.

Tabela 5 - Preços unitários e custos das rações (para 100 kg produzidos em outubro de 2008)

\begin{tabular}{|c|c|c|c|c|c|c|}
\hline \multirow[b]{2}{*}{ Ingrediente } & \multirow{2}{*}{$\begin{array}{c}\text { Valor unitário } \\
\text { (R\$/kg) }\end{array}$} & \multicolumn{5}{|c|}{ Nível de casca de grão de soja (\%) } \\
\hline & & 0 & 25 & 50 & 75 & 100 \\
\hline Feno de aveia & 0,35 & 16,77 & 16,15 & 15,41 & 14,47 & 12,37 \\
\hline Farelo de soja & 0,66 & 12,67 & 11,95 & 11,07 & 9,96 & 8,21 \\
\hline Milho moído & 0,33 & 9,59 & 7,92 & 5,86 & 3,30 & - \\
\hline Casca do grão de soja & 0,27 & - & 2,16 & 4,80 & 8,10 & 13,17 \\
\hline Fosfato bicálcico & 2,03 & - & 0,12 & 0,30 & 0,53 & 0,85 \\
\hline Calcário & 0,03 & 0,02 & 0,02 & 0,02 & 0,01 & - \\
\hline Suplemento mineral & 1,68 & 5,04 & 5,04 & 5,04 & 5,04 & 5,04 \\
\hline Total & & 44,10 & 43,37 & 42,50 & 41,41 & 39,65 \\
\hline
\end{tabular}

A digestibilidade dos nutrientes aumentou até o nível de $75 \%$ de casca do grão de soja nas rações. Contudo, mesmo que não tenha promovido o maior coeficiente de digestibilidade, o custo da ração com a substituição total do milho pela casca do grão de soja foi 10,09\% menor que com a não-inclusão. Assim, é possível afirmar que a relação custo:benefício foi melhor para as rações com $75 \%$ ou $100 \%$ de casca do grão de soja e que a substituição do milho pela casca do grão de soja é economicamente viável, dependendo da sua oferta e valor de mercado, o que determina a sua utilização nas rações.

\section{Conclusões}

A casca do grão de soja pode substituir até $75 \%$ do milho moído em rações para cabritos e pode melhorar a digestibilidade da matéria seca e dos nutrientes, resultando em maior valor energético associado à viabilidade econômica.

\section{Literatura Citada}

GALLOWAY, D.L.; GOETSCH, A.L.; FORSTER, L.A. et al. Feed intake and digestibity by cattle consuming Bermudagrass or Orchardgrass hay supplemented with soybean hulls and (or) corn. Journal of Animal Science, v.71, p.3087-3095, 1993.
GOMES, I.P.O. Substituição do milho pela casca de soja em dietas com diferentes proporções de volumoso:concentrado para bovinos em confinamento. 1998. 84f. Tese (Doutorado em Zootecnia) - Universidade Estadual Paulista/Faculdade de Ciências Agrárias e Veterinárias, Jaboticabal, 1998.

HASHIMOTO, J.H.; ALCALDE, C.R.; ZAMBOM, M.A. et al. Desempenho e digestibilidade aparente em cabritos Boer $\mathrm{x}$ Saanen em confinamento recebendo rações com casca do grão de soja em substituição ao milho. Revista Brasileira de Zootecnia, v.36, n.1, p.174-182, 2007.

HATFIELD, R.D.; WEIMER, P.J. Degradation characteristics of isolated and in situ cell wall lucerne pectic polysaccharides by mixed ruminal microbes. Journal of the Science of Food and Agriculture, v.69, n.2, p.185-196, 1995.

IPHARRAGUERRE, I.R.; CLARK, J.H. Soyhulls as an alternative feed for lactating cows: A review. Journal of Dairy Science, v.86, p.1052-1073, 2003

LUDDEN, P.A.; CECAVA, M.J.; HENDRIX, K.S. The value of soybean hulls as a replacement for corn in beef cattle diets formulated with or without added fat. Journal of Animal Science, v.73, p.2706-2711, 1995.

MENDES, A.R.; EZEQUIEL, J.M.B.; GALATI, R.L. et al. Consumo e digestibilidade aparente total e parcial de dietas utilizando farelo de girassol e três fontes de energia em novilhos confinados. Revista Brasileira de Zootecnia, v.34, n.2, p.679-691, 2005.

NATIONAL RESEARCH COUNCIL - NRC. Nutrients requirements of beef cattle. 7.rev.ed. Washington, D.C.: National Academy Science, 2001. 381p.

NOCEK, J.E. Bovine acidosis: Implications on laminitis. Journal of Dairy Science, v.80, n.5, p.1005-1028, 1997.

PEREIRA, J.R.A.; ROSSI, P. Manual prático de avaliação nutricional de alimentos. 1.ed. Piracicaba: Fundação de Estudos Agrários Luiz de Queiroz, 1995. 34p. 
POORE, M.H.; ECK, T.P.; SWINGLE, R.S. et al. Total starch and relative starch availability of feed grains. In: BIENNIAL CONFERENCE ON RUMEN FUNCTION, 20., 1989, Chicago. Abstracts... Chicago: Society for Rumen Function, 1989. p.10.

SILVA, D.J.; QUEIROZ, A.C. Análise de alimentos: métodos químicos e biológicos. 3.ed. Viçosa, MG: Universidade Federal de Viçosa, 2002. 235p.

SILVA, L.D.F.; EZEQUIEL, J.M.B.; AZEVEDO, P.S. et al. Digestão total e parcial de alguns componentes de dietas contendo diferentes níveis de casca de soja e fontes de nitrogênio, em bovinos. Revista Brasileira de Zootecnia, v.31, n.3, p.1258-1268, 2002.

SNIFFEN, C.J.; O'CONNOR, J.D.; VAN SOEST, P.J. et al. A net carbohydrate and protein system for evaluating cattle diets: II. Carbohydrate and protein availability. Journal of Animal Science, v.70, n.10, p.3562-3577, 1992.

UNIVERSIDADE FEDERAL DE VIÇOSA - UFV. Sistema para análises estatísticas e genéticas - SAEG. Versão 7.1. Viçosa, MG: 1997. 150p.

VAN SOEST, P.J.; ROBERTSON, J.B.; LEWIS, B.A. et al. Symposium: carbohydrate methodology, metabolism, and nutritional implications in dairy cattle. Journal of Dairy Science, v.74, n.10, p.3583-3597, 1991.

ZAMBOM, M.A.; ALCALDE, C.R.; HASHIMOTO, J.H.; et al. Casca do grão de soja em substituição ao milho para cabras Saanen em lactação: curva de lactação, qualidade do leite e análise econômica. In: REUNIÃO ANUAL DA SOCIEDADE BRASILEIRA DE ZOOTECNIA, 46., 2009, Maringá. Anais... Maringá: Sociedade Brasileira de Zootecnia, [2009]. (CD-ROM).

ZAMBOM, M.A.; ALCALDE, C.R.; HASHIMOTO, J.H. et al. Parâmetros digestivos, produção e qualidade do leite de cabras Saanen recebendo rações com casca do grão de soja em substituição ao milho. Acta Scientiarum, v.29, n.3, p.309-316, 2007.

ZAMBOM, M.A.; ALCALDE, C.R.; SILVA, K.T. et al. Desempenho e digestibilidade dos nutrientes de rações com casca do grão de soja em substituição ao milho para cabras Saanen em lactação e no pré-parto. Revista Brasileira de Zootecnia, v.37, n.7, p.1311-1318, 2008.

ZAMBOM, M.A.; SANTOS, G.T.; MODESTO, E.C. et al. Valor nutricional da casca do grão de soja, farelo de soja, milho moído e farelo de trigo para bovinos. Acta Scientiarum, v.23, n.4, p.937-943, 2001. 